\title{
Comparison of Thyroid Imaging Reporting and Data Systems in Malignancy Risk Stratification of Indeterminate Thyroid Nodules
}

\author{
Bo Hyun Kim
}

Department of Internal Medicine, Pusan National University School of Medicine and Biomedical Research Institute, Busan, Korea

The Thyroid Imaging Reporting and Data System (TIRADS) is a quantitative scoring system for risk stratification of thyroid nodules that has played a crucial role in thyroid nodule evaluation and management [1]. Since it was first introduced in 2009 [1], national and international professional organizations have developed their own TIRADS for risk-stratification of thyroid nodules [2-7]. Several comparative studies of various TIRADS' diagnostic performance for malignancy, including meta-analyses, have recently been published [8-18]. Although various TIRADS have similarities in most aspects of their ultrasonography (US) lexicons, significant differences were observed in the classified categories and diagnostic performance of the fine-needle aspiration biopsy (FNAB) criteria for malignancy [17]. Comparative studies have shown that the Korean-TIRADS (K-TIRADS) had the highest sensitivity and highest rate of unnecessary biopsies [13-15,17]. The modified K-TIRADS was also validated to evaluate its diagnostic performance and rate of unnecessary biopsies compared with the 2016 K-TIRADS and other US-based risk stratification systems [18]. Na et al. [17] reported that the modified K-TIRADS reduced the high rate of unnecessary biopsies, while maintaining relatively high sensitivity and diagnostic accuracy for small malignant tumors compared to other risk stratification systems, including the $2016 \mathrm{~K}$ -

\section{TIRADS.}

In light of these results, Kang et al. [19] retrospectively compared the diagnostic performance of the K-TIRADS with that of the American College of Radiology (ACR)-TIRADS for predicting the malignancy risk of indeterminate thyroid nodules at a single referral hospital. They reported that the K-TIRADS and ACR-TIRADS had similar overall sensitivity and specificity for indeterminate thyroid nodules classified as Bethesda categories III, IV, and V. However, unlike ACR-TIRADS, adding K-TIRADS 5 significantly increased the risk of malignancy in nodules classified as Bethesda category III. Therefore, Kang et al. [19] suggested that the K-TIRADS may have further beneficial effects in predicting malignancy risk for Bethesda category III nodules. Similarly, Slowinska-Klencka et al. [20] also recently reported that the K-TIRADS had higher diagnostic efficacy in terms of the area under the curve (AUC) than the ACR-TIRADS in nodules classified as Bethesda category III. However, a meta-analysis of six studies that concluded direct comparisons between the K-TIRADS and ACR-TIRADS showed that the KTIRADS had higher sensitivity than the ACR-TIRADS (0.91 [ $95 \%$ CI, 0.85 to 0.95$]$ vs. 0.85 [ $95 \% \mathrm{CI}, 0.79$ to 0.90$]$ ), but the difference was not statistically significant $(P=0.13)$. Furthermore, the pooled specificity was 0.24 ( $95 \% \mathrm{CI}, 0.19$ to 0.29$)$
Received: 6 October 2021, Accepted: 12 October 2021

Corresponding author: Bo Hyun Kim

Department of Internal Medicine, Pusan National University School of Medicine and Biomedical Research Institute, 179 Gudeok-ro, Seo-gu, Busan 49241, Korea Tel: +82-51-240-7678, Fax: +82-51-254-3237, E-mail: pons71@hanmail.net
Copyright $\odot 2021$ Korean Endocrine Society

This is an Open Access article distributed under the terms of the Creative Commons Attribution Non-Commercial License (https://creativecommons.org/ licenses/by-nc/4.0/) which permits unrestricted non-commercial use, distribution, and reproduction in any medium, provided the original work is properly cited. 
versus 0.57 (95\% CI, 0.47 to 0.66$)(P<0.001)$ [9]. The K-TIRADS and ACR-TIRADS have somewhat different strengths. The K-TIRADS is easier and more intuitive in terms of clinical use in real-world practice because of its pattern-based system according to the echogenicity and solidity of nodules and further analysis of malignant sonographic features [4]. The ACRTIRADS is a point based risk stratification system based on scoring suspicious sonographic features [6]. The ACR-TIRADS has a relatively high size limit of thyroid nodules for which diagnostic FNAB is considered appropriate. Thus, a strength of the ACR-TIRADS is that it reduces unnecessary FNAB [6]. In contrast, the K-TIRADS could have a higher rate of unnecessary FNAB because of its lower size cutoff for biopsies compared with other TIRADS [18]. However, this issue has been overcome in the modified K-TIRADS [17,18]. The modified KTIRADS reduced the unnecessary biopsy rate while maintaining high sensitivity for small malignant thyroid nodules and high sensitivity for large malignant thyroid nodules by increasing the size cutoff for biopsy of K-TIRADS category 3 nodules [17]. However, there are some differences among previous comparative studies regarding the size cutoff of various TIRADS, the method for the final pathologic diagnosis (e.g., surgery or core needle biopsy), and the selection of nodules for analysis in relation to the FNAB category [10-18].

Therefore, further prospective multicenter studies are needed to validate the diagnostic performance of the modified K-TIRADS compared with other TIRADS in various populations with different prevalence rates of papillary thyroid cancer. In addition, further efforts should be made to establish a consensus on a unified risk stratification system.

The management strategy for thyroid nodules has recently become more conservative to minimize the over-diagnosis and over-treatment of small thyroid cancer, which has an indolent disease course. Considering this issue, the modified K-TIRADS will play an essential role in making clinical decisions and optimizing the management of indeterminate thyroid nodules.

\section{CONFLICTS OF INTEREST}

No potential conflict of interest relevant to this article was reported.

\section{ORCID}

Bo Hyun Kim https://orcid.org/0000-0001-9632-9457

\section{REFERENCES}

1. Horvath E, Majlis S, Rossi R, Franco C, Niedmann JP, Castro A, et al. An ultrasonogram reporting system for thyroid nodules stratifying cancer risk for clinical management. J Clin Endocrinol Metab 2009;94:1748-51.

2. Gharib H, Papini E, Garber JR, Duick DS, Harrell RM, Hegedus L, et al. American Association of Clinical Endocrinologists, American College of Endocrinology, and Associazione Medici Endocrinologi Medical Guidelines for clinical practice for the diagnosis and management of thyroid nodules: 2016 update. Endocr Pract 2016;22:622-39.

3. Haugen BR, Alexander EK, Bible KC, Doherty GM, Mandel SJ, Nikiforov YE, et al. 2015 American Thyroid Association management guidelines for adult patients with thyroid nodules and differentiated thyroid cancer: the American Thyroid Association guidelines task force on thyroid nodules and differentiated thyroid cancer. Thyroid 2016;26:1133.

4. Shin JH, Baek JH, Chung J, Ha EJ, Kim JH, Lee YH, et al. Ultrasonography diagnosis and imaging-based management of thyroid nodules: revised Korean Society of Thyroid Radiology Consensus Statement and Recommendations. Korean J Radiol 2016;17:370-95.

5. Russ G, Bonnema SJ, Erdogan MF, Durante C, Ngu R, Leenhardt L. European Thyroid Association guidelines for ultrasound malignancy risk stratification of thyroid nodules in adults: the EU-TIRADS. Eur Thyroid J 2017;6:225-37.

6. Tessler FN, Middleton WD, Grant EG, Hoang JK, Berland LL, Teefey SA, et al. ACR Thyroid Imaging, Reporting and Data System (TI-RADS): white paper of the ACR TI-RADS Committee. J Am Coll Radiol 2017;14:587-95.

7. Zhou J, Yin L, Wei X, Zhang S, Song Y, Luo B, et al. 2020 Chinese guidelines for ultrasound malignancy risk stratification of thyroid nodules: the C-TIRADS. Endocrine 2020;70: 256-79.

8. Castellana M, Grani G, Radzina M, Guerra V, Giovanella L, Deandrea M, et al. Performance of EU-TIRADS in malignancy risk stratification of thyroid nodules: a meta-analysis. Eur J Endocrinol 2020;183:255-64.

9. Li W, Wang Y, Wen J, Zhang L, Sun Y. Diagnostic performance of American College of Radiology TI-RADS: a systematic review and meta-analysis. AJR Am J Roentgenol 2021;216:38-47.

10. Kim PH, Suh CH, Baek JH, Chung SR, Choi YJ, Lee JH. Diagnostic performance of four ultrasound risk stratification 
systems: a systematic review and meta-analysis. Thyroid 2020;30:1159-68.

11. Magri F, Chytiris S, Croce L, Molteni M, Bendotti G, Gruosso G, et al. Performance of the ACR TI-RADS and EU TI-RADS scoring systems in the diagnostic work-up of thyroid nodules in a real-life series using histology as reference standard. Eur J Endocrinol 2020;183:521-8.

12. Yim Y, Na DG, Ha EJ, Baek JH, Sung JY, Kim JH, et al. Concordance of three international guidelines for thyroid nodules classified by ultrasonography and diagnostic performance of biopsy criteria. Korean J Radiol 2020;21:108-16.

13. Ha EJ, Na DG, Baek JH, Sung JY, Kim JH, Kang SY. US fine-needle aspiration biopsy for thyroid malignancy: diagnostic performance of seven society guidelines applied to 2000 thyroid nodules. Radiology 2018;287:893-900.

14. Ha EJ, Na DG, Moon WJ, Lee YH, Choi N. Diagnostic performance of ultrasound-based risk-stratification systems for thyroid nodules: comparison of the 2015 American Thyroid Association guidelines with the 2016 Korean Thyroid Association/Korean Society of Thyroid Radiology and 2017 American College of Radiology Guidelines. Thyroid 2018; 28:1532-37.

15. Middleton WD, Teefey SA, Reading CC, Langer JE, Beland MD, Szabunio MM, et al. Comparison of performance characteristics of American College of Radiology TI-RADS, Korean Society of Thyroid Radiology TIRADS, and Ameri- can Thyroid Association Guidelines. AJR Am J Roentgenol 2018;210:1148-54.

16. Xu T, Wu Y, Wu RX, Zhang YZ, Gu JY, Ye XH, et al. Validation and comparison of three newly-released Thyroid Imaging Reporting and Data Systems for cancer risk determination. Endocrine 2019;64:299-307.

17. Na DG, Paik W, Cha J, Gwon HY, Kim SY, Yoo RE. Diagnostic performance of the modified Korean Thyroid Imaging Reporting and Data System for thyroid malignancy according to nodule size: a comparison with five society guidelines. Ultrasonography 2021;40:474-85.

18. Chung SR, Ahn HS, Choi YJ, Lee JY, Yoo RE, Lee YJ, et al Diagnostic performance of the modified Korean Thyroid Imaging Reporting and Data System for Thyroid Malignancy: a multicenter validation study. Korean J Radiol 2021;22: 1579-86.

19. Kang S, Kwon SK, Choi HS, Kim MJ, Park YJ, Park DJ, et al. Comparison of Korean vs. American Thyroid Imaging Reporting and Data System in malignancy risk assessment of indeterminate thyroid nodules. Endocrinol Metab (Seoul) 2021:36:1111-20.

20. Slowinska-Klencka D, Wysocka-Konieczna K, Klencki M, Popowicz B. Diagnostic value of six Thyroid Imaging Reporting and Data Systems (TIRADS) in cytologically equivocal thyroid nodules. J Clin Med 2020;9:2281. 